\title{
Quantificação computadorizada dos índices de placa e cálculo dentais da imagem digital da superfície vestibular dos dentes de cães ${ }^{1}$
}

\author{
Samira L. Abdalla ${ }^{2 \star}$, Marta F.A. Silva ${ }^{3}$, Ana Rita C. Pereira ${ }^{4}$, Felipe D. \\ Azevedo ${ }^{2}$, Júlio I. Fernandes ${ }^{2}$, Guilherme P. Minono ${ }^{4}$ e Rosana P. Botelho ${ }^{3}$
}

\begin{abstract}
Abdalla S.L., Silva M.F.A., Pereira A.R.C., Azevedo F.D., Fernandes J.I., Minono G.P. \& Botelho R.P. 2009. [Computer quantification for the evaluation of dental plaque and dental calculus index in the digital image of vestibular surface of the teeth of dogs.] Quantificação computadorizada dos índices de placa e cálculo dentais da imagem digital da superfície vestibular dos dentes de cães. Pesquisa Veterinária Brasileira 29(8):666-672. Departamento de Medicina e Cirurgia Veterinária, Instituto de Veterinária, Universidade Federal Rural do Rio de Janeiro, Seropédica, RJ 23890-000, Brazil. E-mail: abdallasamira@ hotmail.com

Periodontal disease is caused by dental plaque accumulation on teeth and adjacent structures. Indices have been formulated for its measurement considering the amount and intensity of dental plaque (DP) and dental calculus (C) on the surface of teeth through subjective visual evaluation. This study aims at assessing the computerized analysis method for measurement of DP and $\mathrm{C}$ areas on the teeth of dogs by comparing it with the visual evaluation in the oral cavity. Ten beagle dogs with similar characteristics and kept under the same management and diet were used. Evaluations of oral cavity occurred before surgical prophylaxis (performed under general inhalation anesthesia) and after seven days for DP and 28 days for $\mathrm{C}$. The computerized $\mathrm{C}$ area evaluation showed to be statistically better than the visual evaluation before and after prophylaxis. It was concluded that the computerized evaluation is beneficial when compared to visual evaluation, providing greater precision in the area measurement.
\end{abstract}

INDEX TERMS: Diseases of dogs, dental plaque, dental calculus.

RESUMO.- A doença periodontal é causada pelo acúmulo de placa bacteriana sobre os dentes e estruturas adjacentes. Para sua mensuração têm sido formulados índices que consideram a quantidade e intensidade de placa bacteriana $(P B)$ e de cálculo dental $(C D)$ existentes na superfície dentária por meio de avaliação visual subjetiva. O presente estudo tem como objetivo avaliar o método de análise computadorizada para medição de área de PB e CD nos dentes de cães através da comparação com

\footnotetext{
${ }^{1}$ Recebido em 17 de fevereiro de 2009.

Aceito para publicação em 28 de março de 2009.

2 Curso de Pós-Graduação em Ciências Veterinárias, Universidade Federal Rural do Rio de Janeiro (UFRRJ), Seropédica, RJ 23890-000, Brasil. *Autor para correspondência: abdallasamira@ hotmail.com

${ }^{3}$ Departamento de Medicina e Cirurgia Veterinária, Instituto de Veterinária, UFRRJ, Seropédica, RJ.

${ }^{4}$ Graduandos em Medicina Veterinária, UFRRJ, Seropédica, RJ.
}

a avaliação visual. Foram utilizados 10 cães Beagles, três machos e sete fêmeas, com similares características e mantidos sob o mesmo manejo e dieta alimentar. As avaliações das superfícies vestibulares dos dentes ocorreram antes da profilaxia dentária, que foi realizada sob anestesia geral inalatória, e após sete dias para PB e após 28 dias para CD. A avaliação computadorizada da área de CD demonstrou ser estatisticamente melhor em relação à avaliação visual antes e após a profilaxia; entretanto, não demonstrou diferença significante na avaliação da PB. Concluiu-se que a avaliação computadorizada é vantajosa em relação à visual por conferir maior precisão na obtenção da proporção entre área total do dente e área acometida, mostrando-se estatistticamente superior na quantificação do CD após 28 dias.

TERMOS DE INDEXAÇÃO: Doenças de cães, placa bacteriana, cálculo dental. 


\section{INTRODUÇÃO}

A doença periodontal (DP) apresenta alta incidência em cães (Harvey \& Emily 1993). O cálculo dental (CD) e a gengivite são as doenças que mais acometem os cães (Lund et al. 1999). A causa da DP é a placa bacteriana (PB) (Löe 1967), que se estabelece entre 24-48 horas após a profilaxia da superfície dental (Gioso 2007). Se o acúmulo da PB não for controlado, ocorre progressão da $\mathrm{DP}$, em geral sem regeneração e incurável devido à resposta inflamatória individual que resulta em destruição do periodonto com perdas funcional e dentária (Harvey \& Emily 1993, DuPont 1997, Stoeken et al. 2007). Complicações sistêmicas devidas à bacteremia e absorção de toxinas bacterianas oriundas da cavidade oral são relatadas como possíveis responsáveis por alterações no coração, nos rins, no fígado (Debowes et al. 1996) e nas articulações (Gioso 2007).

Úma limitação da análise da DP é a imprecisão dos dados obtidos pela avaliação visual humana e a necessidade de que os avaliadores sejam bem treinados e padronizados. Vários índices que medem o acúmulo de PB e gengivite em humanos têm sido propostos, mas poderia ser benéfico considerar-se um novo sistema de mensuração em cães (Hennet 1999). A avaliação visual pode-se tornar não-representativa, pois as formas irregulares dos dentes tornam difícil a avaliação objetiva da área, e a aplicação apropriada dos índices utilizados em humanos e modificados para o uso em cães e gatos tem sido questionada (Harvey 2002).

A inovação no método de avaliação com a utilização de programas computadorizados traz a precisão matemática para a análise do índice de PB e do índice de CD. Desse modo, apenas um avaliador e uma medição serão necessários. Esse método pode contribuir para que as novas pesquisas de avaliação da progressão da DP e da inibição do biofilme bacteriano dental, com a utilização de produtos odontológicos veterinários específicos, sejam seguras e precisas, além de serem fornecidos subsídios para uso em outras espécies.

O presente estudo tem por objetivo avaliar o método de análise computadorizada, utilizando-se os programas gratuitos GIMP2 e Image J para medição de área de PB e CD em cães Beagle e compará-lo ao método de avaliação visual.

\section{MATERIAL E MÉTODOS}

Foram utilizados 10 cães (três machos e sete fêmeas) da raça Beagle provenientes do canil de experimentação do Laboratório de Quimioterapia Experimental em Parasitologia Veterinária do Departamento de Parasitologia Animal da Universidade Federal Rural do Rio de Janeiro. Com média de idade de dois anos e quatro meses (idades entre um ano e quatro anos e sete meses) e peso médio de $10 \mathrm{~kg}$. Os cães tinham conformações de crânio, mesaticefálicos, normoclusão e todos os dentes avaliados intactos. O temperamento dócil dos cães permitiu a manipulação oral sem grandes dificuldades.

Os cães foram mantidos sob condições padronizadas de manejo e alimentação com ração comercial seca e água fresca ad libitum, em conformidade com o que recomenda o Veterinary Oral Health Council (VOHC 2008) para realização de experimentos relacionados com PB e CD. O projeto foi aprovado pelo Comitê de Ética do Instituto de Veterinária da Universidade Federal Rural do Rio de Janeiro. Foram incluídos os cães que apresentaram até o grau III de doença periodontal (gengivite severa, presença ou não de CD, edema acentuado, gengivas vermelho ou púrpura com enrolamento acentuado de margem, presença de bolsas gengivais de 4-6 mm de profundidade, dentes bem firmes) de acordo com a classificação anteriormente publicada (Beard \& Beard 1989). Foi observada gengivite leve em todos os cães e cálculo em todos os dentes avaliados. Constatou-se a higidez dos cães através de exames físicos e laboratoriais.

A avaliação seguiu o modelo já publicado (Logan \& Boyce 1994) e foram avaliados os seguintes dentes no dia zero: terceiro incisivos, caninos, $1^{\circ}, 2^{\circ}, 3^{\circ}$ e $4^{\circ}$ pré-molares maxilares e caninos, $2^{\circ}$, $3^{\circ}$ e $4^{\circ}$ pré-molares e primeiro molar mandibular. Todas as observações quanto à profundidade de bolsas periodontais e grau de gengivite e os índices de PB e CD de acordo com a avaliação visual foram registradas no odontograma (Corrêa et al. 1998).

Para a profilaxia cirúrgica utilizou-se como medicação préanestésica acepromazina ${ }^{5}\left(0,1 \mathrm{mg} \cdot \mathrm{kg}^{-1} \mathrm{IV}\right)$; a indução anestésica foi realizada com tiopental sódico ${ }^{6}\left(12,5 \mathrm{mg} \cdot \mathrm{kg}^{-1} \mathrm{IV}\right)$ e a manutenção com halotano ${ }^{7}$ em sistema de baraka, aberto, sem reinalação do anestésico (Massone 1994, Fantoni \& Cortopassi 2002). Previamente à profilaxia da cavidade oral foi realizada a anti-sepsia com solução de clorexidina a $0,12 \%$, também para proteção da equipe de médicos veterinários (Bowersock et al. 2000, Michell 2005).

As avaliações visuais da PB presente no dia zero e formada sete dias após a profilaxia foram realizadas sempre pelo mesmo avaliador e no mesmo local, diretamente nos cães, após coloração com eosina aquosa a 2\% (Logan \& Boyce 1994), suavemente aplicada com o auxílio de algodão sobre a superfície da coroa dos dentes e de imediato lavada com água com o auxílio de seringa descartável de $10 \mathrm{~mL}$. Esse procedimento foi realizado pela manhã, no canil de experimentação, ao abrigo da luz solar direta, entre seis e oito horas. A determinação do índice de área de placa bacteriana (IAPB) baseou-se em um sistema anteriormente publicado (Logan \& Boyce 1994), considerando-se o percentual de área acometida pela placa em relação à superfície vestibular total de cada dente avaliado, com cinco níveis de escores ( 0 a 4), conforme apresentado no Quadro 1. Os escores de cada dente foram somados e divididos pelo número de dentes avaliados, para obter-se o IAPB da cavidade oral de cada cão. Nos dias zero e 28 , foram realizadas as avaliações de $C D$, no mesmo horário e local descritos para avaliação de PB, e sempre pelo mesmo avaliador, através da observação direta da cavidade oral dos cães. Foi seguida a mesma metodologia descrita para a avaliação de PB (Logan e Boyce 1994) e, da mesma forma, foram determinados os índices de área de cálculo (IAC), da cavidade oral de cada cão.

\footnotetext{
${ }^{5}$ Acepran ${ }^{1} 1,0 \%$, Univet S.A. Indústria Veterinária, Rua Clímaco Barbosa 700 , São Paulo, SP

6 Tiopental®, Cristália Produtos Químicos Farmacêuticos Ltda, Rodovia Itapira-Lindóia, Km 14, Itapira, SP.

${ }^{7}$ Fluothane, Cristália Produtos Químicos Farmacêuticos Ltda, Rodovia Itapira-Lindóia, Km 14, Itapira, SP.
} 
Quadro 1. Sistema de índice de cálculo e de placa bacteriana segundo Logan \& Boyce (1994)

\begin{tabular}{cc}
\hline Índice & $\begin{array}{c}\text { Percentagem de superfície } \\
\text { dental acometida }\end{array}$ \\
\hline 0 & 0 \\
1 & $1 \%-24 \%$ \\
2 & $25 \%-49 \%$ \\
3 & $50 \%-74 \%$ \\
4 & $75 \%-100 \%$ \\
\hline
\end{tabular}

${ }^{\mathrm{a} A}$ área da superfície vestibular da coroa dental acometida em relação à superfície vestibular total é determinada atribuindo-se um escore de acordo com os dados dos intervalos de percentagem.

\section{Quadro 2. Sistema de índice de cálculo dental (CD) e de placa bacteriana (PB) modificado de Logan \& Boyce}

\begin{tabular}{cc}
\hline Índice & $\begin{array}{c}\text { Percentagem de superfície } \\
\text { dental acometida }\end{array}$ \\
\hline 0 & 0 \\
1 & $0<\mathrm{a}<25$ \\
2 & $25 \leq \mathrm{a}<50$ \\
3 & $50 \leq \mathrm{a}<75$ \\
4 & $75 \leq \mathrm{a} \leq 100$ \\
\hline
\end{tabular}

${ }^{a} \mathrm{~A}$ área da superfície vestibular da coroa dental acometida em relação à superfície vestibular total é determinada através do programa Broffice.org Calc obtendo-se o valor da percentagem de PB e da percentagem de CD, atribuindo-se um escore de acordo com os dados dos intervalos de percentagem.

Para a avaliação computadorizada, fotografias digitais da cavidade oral de cada cão foram obtidas nos dias zero, sete e 28 para obtenção do IAPB e IAC, conforme Quadro 2. As fotos foram realizadas antes e após coloração com eosina aquosa a $2 \%$, com os seguintes parâmetros: resolução de $2364 \times 1728$, opções macro e flash acionadas, distância da câmera em relação aos dentes proporcional ao campo visual desejado, eixo da lente objetiva da máquina fotográfica direcionado perpendicular à superfície vestibular dos dentes e, no mesmo plano dos dentes avaliados, alocada uma régua milimetrada para evitar erros causados por distorções e permitir a calibração da mensuração linear e da área do dente na imagem. As imagens digitalizadas foram analisadas em computador com o auxílio dos programas gratuitos GIMP $2^{8}$ (Fig.1-5) para tratar a imagem, do Image ${ }^{\rho}$ para se obter as mensurações e do Broffice.org Calc ${ }^{10}$ para se obter as percentagens das áreas das superfícies vestibulares dos dentes acometidos por placa ou cálculo em relação à área total de cada dente. As imagens digitalizadas das superfícies vestibulares dos dentes das maxilas direita e esquerda e das mandíbulas direita e esquerda foram tratadas no programa GIMP 2 para obter-se uma única cor na área de

8 GIMP2, programa de computador obtido em 10.01.07. Acessar a página: www.gimp.org/windows; clicar em "Installer"; onde está escrito "GIMP for Windows", clicar em "Download"; após terminado o download do instalador, o programa, com cerca de $18 \mathrm{Mbytes}$, deve ser executado para que o aplicativo seja instalado.

9 Image J, programa de computador obtido em 10.01.07. Acessar a página: http://rsb.info.nih.gov/ij/; clicar em "Download"; onde está escrito "Windows" clicar no link de nome "bundled with Java 1.6.0 05"; após terminado o download do instalador, o programa, com cerca de 21 MBytes, deve ser executado para que o aplicativo seja instalado.

10 Broffice.org Calc, programa de computador obtido em 10.1.07. Acessar a página: www.broffice.org

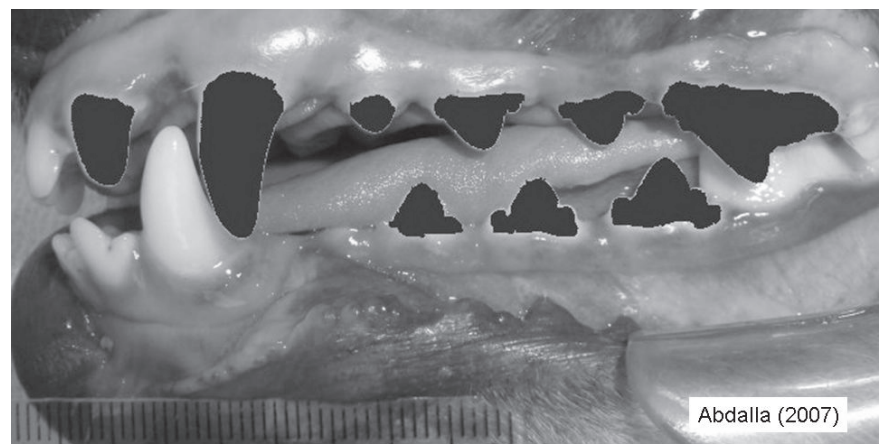

Fig.1. Imagem digitalizada da superfície vestibular dos dentes da maxila e mandíbula esquerda da cavidade oral de cão, tratada no programa GIMP2 após colorir-se de azul escuro as áreas totais dos dentes.

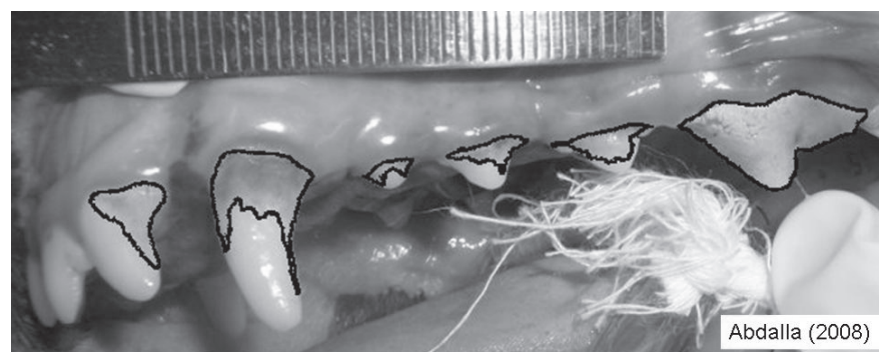

Fig.2. Imagem digitalizada da superfície vestibular dos dentes da maxila esquerda da cavidade oral de cão, tratada no programa GIMP2 após contornarem-se as áreas acometidas por cálculo dentário no dia zero.

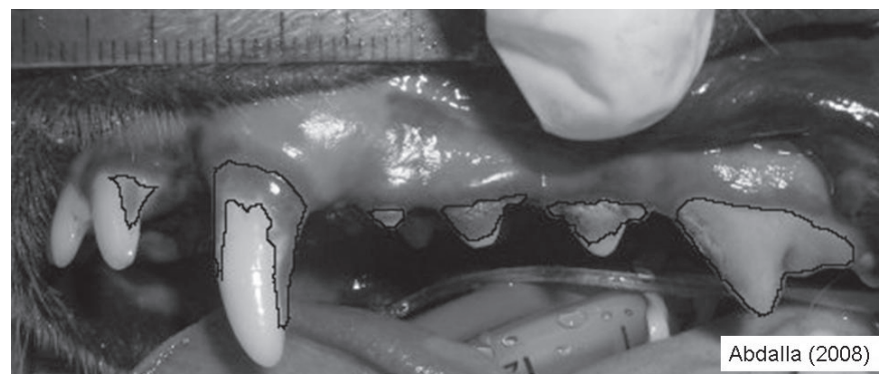

Fig.3. Imagem digitalizada da superfície vestibular dos dentes da maxila esquerda da cavidade oral de cão, tratada no programa GIMP2 após contornarem-se as áreas coradas com eosina a $0,2 \%$ acometidas por placa bacteriana no dia zero.

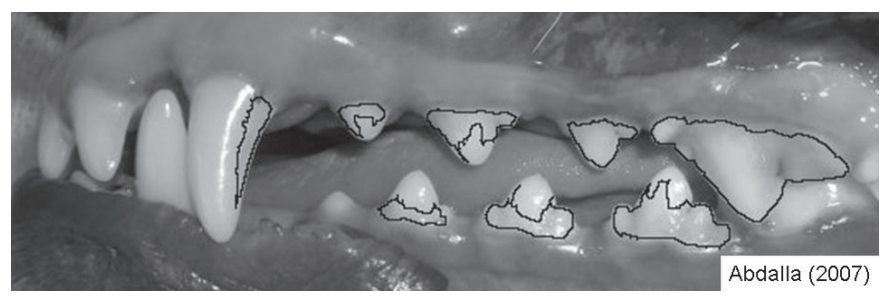

Fig.4. Imagem digitalizada da superfície vestibular dos dentes da maxila e mandíbula esquerda da cavidade oral de cão, tratada no programa GIMP2 após contornarem-se as áreas coradas com eosina a $0,2 \%$ acometidas por placa bacteriana no sétimo dia após a profilaxia da cavidade oral. 


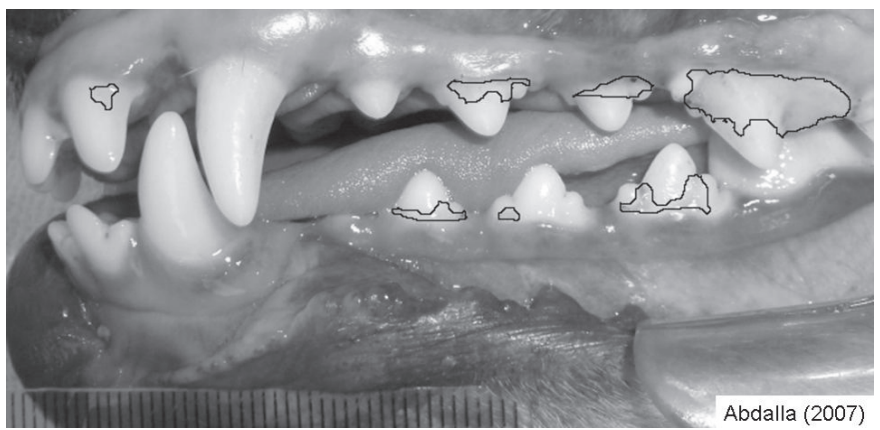

Fig.5. Imagem digitalizada da superfície vestibular dos dentes da maxila e mandíbula esquerda da cavidade oral de cão, tratada no programa GIMP2 após contornarem-se as áreas acometidas por cálculo dental, 28 dias após a profilaxia da cavidade oral.

PB, cálculo e área total. Para isso foi acompanhado o seguinte tutorial: (1) menu: arquivo/abrir: selecionar o arquivo da foto a ser trabalhada; (1.1) menu: arquivo/salvar como: onde está escrito "tipo de preenchimento", selecione "GIMP XCF Image", o que modificará a extensão do nome do arquivo para ".xcf"; clique em "salvar"; (2) menu: imagem/redimensionar imagem: largura 800, altura 600 e selecione a opção de interpolação "cúbica (melhor)"; (3) menu: visualizar/zoom/200\%; (4) menu: ferramentas/ferramentas de seleção/seleção contígua; (4.1) menu: diálogos/opções de ferramentas: garanta que a opção "suavizar" está desmarcada; (5) identifique a área da imagem que apresenta PB e cálculo para que seja feita a seleção; (5.1) mantendo a tecla SHIFT (adicionar seleção) pressionada durante todo o tempo, clique com o mouse na área que se deseja selecionar, de apenas um dente; (5.2) menu: seleção/ligar des. máscara rápida; observar que toda a imagem ficou com uma "máscara avermelhada" por cima, e apenas a área que foi selecionada ficou descoberta; aumente o zoom para $400 \%$ para facilitar a precisão no manuseio; para acrescentar máscara use a ferramenta - menu: ferramentas/ferramentas de pintura/pincel; para remover máscara use a ferramenta - menu: ferramentas/ferramentas de pintura/borracha. observar que tanto o pincel quanto a borracha tem um tamanho que pode ser modificado em - menu: diálogos/pincéis; estando a máscara de seleção bem definida, desligue a "mascara rápida" e veja como ficou a seleção em si, podendo religá-la e repetir o procedimento acima; (5.3) menu: camada/nova camada: com a opção "transparência" marcada; isso criará uma nova "camada" de imagem, ou seja, uma imagem transparente por cima da foto que está sendo tratada, que passará a ser a camada de trabalho ativa; ()5.4) menu: diálogos / cores; determinar cores distintas para cada tipo de análise (PB ou CD); (5.5) utilizando a ferramenta "pincel" na nova camada, pinte completamente a parte de dentro da área que foi preparada (observe que todo este procedimento deve ser repetido para se preparar as áreas totais de cada dente, numa nova camada de imagem transparente, em cor distinta das demais, agora representando "área total do dente"); (6) inicia-se então o preparo para a medição da área, com base na régua milimetrada que foi incluída na foto; (6.1) menu: diálogos/camadas: selecione a camada da foto, que é a de fundo; (O6.2) menu: ferramentas/ferramentas de seleção/ seleção retangular; selecione $1 \mathrm{~cm}$ (um centímetro) completo da régua, podendo ultrapassar; (6.3) tecle: $C t r l+C$ (copiar), Ctrl+V (colar), vá no navegador de camadas e observe que aparece uma nova camada de nome "seleção flutuante (camada colada)", clique com o botão direito do mouse e selecione "nova camada" - isto transformará a camada flutuante numa camada real; (6.4) menu: imagem/guias/nova guia: clique em ok, observe que apareceu uma guia pontilhada em azul e preto, na horizontal, no topo da foto - esta guia não faz parte da imagem, é apenas uma "linha guia"; (6.5) menu: ferramentas/ ferramentas de transformação / mover: posicione o mouse em cima da "linha guia", clique e arraste, movendo-a até que se alinhe com $0,5 \mathrm{~cm}$ (a extremidade do indicador de $0,5 \mathrm{~cm}$ na régua milimetrada da foto); (6.6) menu: camada/transformar/rotação livre: observe que apesar de ter aparecido uma janela de diálogo para rotação da camada, ela pode ser arrastada para o lado a imagem então passa a apresentar quatro pequenos quadrados, um em cada extremidade do centímetro da régua que foi copiada; posicione o mouse num desses quadrados, clique e arraste; a imagem irá rotacionar e, fazendo uso da linha guia, consegue-se rotacionar a régua perfeitamente para a horizontal; com Alt+TAB, volte na janela de diálogo de rotação e clique em rotacionar; (6.7) no navegador de camadas há um pequeno olho do lado esquerdo de cada camada - clique no que se refere à camada de fundo da foto - ficarão visíveis apenas as camadas da seleção que foi pintada e do pedaço da régua que foi copiado e rotacionado para a horizontal; (6.8) menu: arquivo/ salvar uma cópia: na opção "tipo de preenchimento", selecione "imagem GIF" e, na parte de cima da tela, modifique o nome do arquivo da foto para "nome_PB.gif" (ou "nome_Calculo.gif", ou "nome_AreaTotal.gif", dependendo do que estiver sendo preparado no momento); clique em "Salvar"; clique em "Exportar"; clique em "OK"; (7) pode ser fechado o aplicativo GIMP.

Para obtenção das medidas das áreas em $\mathrm{cm}^{2}$ foi então utilizado o programa ImageJ, acompanhando-se o seguinte tutorial: (1) menu: file/open: selecione o arquivo ".gif" resultante do trabalho com o Gimp; (2) posicione o mouse na foto, na marcação do início do "um centímetro" que foi anteriormente copiado e rotacionado pelo Gimp; observe que na janela principal do ImageJ, aparece no rodapé a indicação, por exemplo: " $x=430, y=. .$. " - então, anote/decore o valor de " $x$ "; (2.1) posicione o mouse no final desse "um centímetro" e anote o novo valor de "x", por exemplo: "x=550, ..."; subtraia deste o valor o " $x$ " anotado anteriormente; obtem-se assim o valor, por exemplo: "120", o qual é a quantidade de pixels/pontos na imagem que corresponde a $1 \mathrm{~cm}$; observar que essa informação só é valida para a foto corrente, devendo ser recalculada para cada nova foto, garantindo-se a precisão; (2.2) menu: analyze/set scale: ajuste "distance in pixels" para valor que foi calculado - por exemplo: 120; garanta que em "unit of length" esteja escrito "cm"; clique em "ok"; (2.3) clicar no ícone de ferramenta "wand (tracing) tool"; então clique dentro da área que do dente que foi pintada, o que fará com que o contorno dessa área seja selecionado em amarelo. (2.4) menu: analyze/measure: observe que apareceu uma nova janela, com a coluna "area", e com o valor calculado em $\mathrm{cm}^{2}$, por exemplo: 0,0861 (sim, é de alta precisão); (2.5) clique na área de outro dente (caso haja) e novamente em "measure", e assim a tabela de medições será preenchida aos poucos. Esse procedimento completo do ImageJ deve ser repetido para a área total dos dentes.

Os dados de área parcial e total foram levados ao programa Broffice.org Calc, para obtenção do percentual de área de PB $(\% \mathrm{~PB})$ ou de $\mathrm{PC}(\% \mathrm{C})$ em relação à área total de cada superfície vestibular dos dentes acometidos. Para análise estatística dos resultados, os valores obtidos da avaliação visual e com- 
putadorizada foram comparados através do Teste t de Student com valores de significância abaixo de 0,05.

\section{RESULTADOS}

Não houve diferença estatisticamente significante no Teste t de Student entre as avaliações visual e computadorizada na observação da placa bacteriana, tanto no dia zero (anteriormente à profilaxia) quanto no dia sete. Na observação de cálculo dental houve diferença significante nos dois julgamentos, com nível de significância menor que 0,05 no dia zero $(p=0,0115)$ e menor que 0,01 no dia 28 ( $p=0,0023$ ) (Quadro 3).

\begin{tabular}{|c|c|c|c|c|c|c|c|}
\hline & $\begin{array}{l}\text { IAF } \\
\text { Dia }\end{array}$ & $\begin{array}{l}\text { PB }^{a} \\
\text { zero }\end{array}$ & $\begin{array}{l}\text { IA } \\
\text { Dia }\end{array}$ & $\begin{array}{l}\text { PB } \\
\text { sete }\end{array}$ & $\begin{array}{l}\text { IA } \\
\text { Dia }\end{array}$ & $\begin{array}{l}\mathrm{C}^{\mathrm{b}} \\
\text { zero }\end{array}$ & $\begin{array}{c}\text { IAC } \\
\text { Dia } 28\end{array}$ \\
\hline & $A V^{c}$ & $A C^{d}$ & $\mathrm{AV}$ & $A C$ & AV & $A C$ & AV $\quad A C$ \\
\hline Média & 3,42 & 3,31 & 2,31 & 2,44 & 3,07 & 2,76 & $2,67 \quad 2,18$ \\
\hline Desvio padrão & 0,19 & 0,15 & 0,68 & 0,50 & 0,27 & 0,34 & $0,41 \quad 0,49$ \\
\hline $\begin{array}{l}\text { Teste t de } \\
\text { Student }\end{array}$ & $\mathrm{p}=0$, & 1458 & $p=0$ & 5892 & $\mathrm{p}=0$, & 0115 & $p=0,0023$ \\
\hline
\end{tabular}

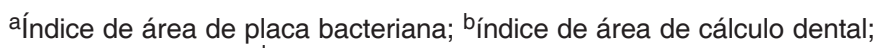
cavaliação visual; davaliação computadorizada.

\section{DISCUSSÃO E CONCLUSÃO}

A escolha de cães Beagle foi bastante favorável neste experimento por propiciar a padronização de conformação de crânio e oclusão, além de ser a raça mais utilizada em estudos de doença periodontal, incluindo estudos veterinários sobre redução de placa bacteriana (PB) e cálculo dental (CD) (Gorrel \& Rawlings 1996). É relatado na literatura que estudos epidemiológicos e clínicos têm estabelecido que a etiologia, patologia e progressão da doença periodontal em cães e humanos exibem similaridades (Hull \& Davies 1972), o que tem feito com que o cão seja utilizado como modelo experimental também para a espécie humana, expandindo, portanto, a abrangência desse estudo. Avaliações após a profilaxia da cavidade oral foram feitas nos dias sete para PB e 28 para CD, considerando-se o preconizado pelo VOHC (2008); outros estudos utilizaram esse mesmo protocolo de datas para avaliações (Lindhe et al. 1975, Gorrel \& Rawlings 1996, Rawlings et al. 1998, Scherl et al. 2007) levando em conta observações de patofisiologia da evolução da DP. Neste estudo, foi necessário apenas um avaliador, devido à avaliação ter sido pelo método computadorizado, contrariando o $\mathrm{VOHC}$ (VOHC 2008), que preconiza a necessidade de mais de um avaliador bem treinado para as avaliações visuais, esse fator foi o que motivou o desenvolvimento do presente estudo. Alguns autores (Logan \& Boyce 1994) afirmam que o fator chave no desenvolvimento e uso de um sistema de escore válido é o uso de examinadores consistentes; qualquer método utilizado requer examinadores bem treinados, mas sempre haverá intra e intervariabilidade dos avaliadores e o uso dos mesmos avaliadores durante todo estudo é a abordagem usualmente utilizada para minimizar essa variabilidade. No estudo de outros autores (Scherl et al. 2007) também foi utilizado apenas um avaliador, quando foi aplicado um novo método de quantificação de PB. Para avaliação da área da superfície vestibular dental acometida seguiu-se metodologia previamente descrita (Logan \& Boyce 1994), porém modificada (Harvey 2002, Hennet et al. 2006, VOHC 2008), na qual a superfície vestibular dental foi aferida como área total, sem divisão das coroas dentárias em três regiões, considerando-se o mencionado em estudo anterior (Harvey 2002), isto é, que a segmentação dificultaria consistentemente a avaliação, podendo resultar em representação desproporcional de muitas áreas segmentadas. Existem dificuldades a serem ultrapassadas nos dois métodos de avaliação - visual e computadorizada. Para realização da avaliação computadorizada há demanda de tempo para o aprendizado do manuseio dos programas de computador (GIMP2 e ImageJ) e para a realização das avaliações, que foi diminuindo à medida que se conseguiu habilidade. Deve-se levar em conta também a necessidade de uma máquina digital fotográfica de no mínimo cinco mega pixels e cartão de dois giga de memória, computador com uma capacidade de memória Ram de no mínimo 512 MB para suportar abertos, ao mesmo tempo, os programas para tratamento das imagens, o que, entretanto, não se caracteriza como dificuldade, uma vez que estes equipamentos estão geralmente disponíveis em instituições de pesquisa. Além disto, quando as fotos foram realizadas, ocorreu uma distorção rotacional do terceiro incisivo maxilar, o que já havia sido descrito (Harvey 2002) quando se usa uma única imagem digitalizada com todos os dentes aferidos, devido ao arco dental formado pelos dentes rostrais não estar no mesmo plano que os dentes caudais; para obter-se a imagem digital da superfície vestibular do terceiro incisivo a foto deveria ser realizada frontalmente e não lateralmente. Esses fatores não foram observados em relação à avaliação visual, pois após o aprendizado da técnica, o material necessário constituía-se apenas de lápis e papel ofício, utilizados imediatamente após o animal ser contido manualmente, e a distorção da imagem do terceiro incisivo maxilar pode ser corrigida pelo posicionamento do observador.

Outro aspecto a ser considerado é a utilização da câmera digital sem necessidade de fixação da distância em relação à superfície vestibular dos dentes. Isto foi possível devido à colocação de uma régua no mesmo plano da superfície vestibular, o que permitiu a correção da distorção de tamanho dos dentes e conseqüentemente das áreas a serem mensuradas, pois foram comparados com a distância de um centímetro da régua na mesma imagem digital. Os resultados no presente estudo foram obtidos da proporção entre as medidas de área total e área de placa ou cálculo em cada dente avaliado, o que minimiza ou anula a importância de possíveis variações 
devidas a, por exemplo, angulação da câmera em relação aos dentes e distorção da imagem a partir do redimensionamento da mesma para análise digital.

A diferença estatisticamente significante observada na comparação entre a avaliação visual e computadorizada com os valores de IAC nos dias zero e 28 , demonstra que a mesma pode conferir maior objetividade à análise, devido à possibilidade de se conseguir selecionar e medir, com o uso dos programas GIMP2, ImageJ e BrOffice.org Calc, a área acometida por CD com maior definição. Além disso, são obtidos valores precisos, podendo-se, através de estudos complementares, substituir a utilização de índices por percentual de área ou, ainda, definir outro sistema de escores que utilize faixas de percentuais de áreas menores do que as disponíveis na literatura, (Logan \& Boyce 1994).

A determinação das áreas de placa e cálculo através do programa de computador é definida automaticamente pela coloração diferenciada em relação à área normal do dente, o que diminui drasticamente a subjetividade do avaliador. A maior precisão da avaliação computadorizada indica que pode ser dispensada a necessidade de pelo menos dois avaliadores para a obtenção dos resultados, conforme é preconizado na avaliação visual, o que deve ser confirmado através de estudos complementares. No mesmo tipo de análise, em relação à $\mathrm{PB}$, não foi observada diferença estatisticamente significante entre as avaliações visual e computadorizada, o que pode ser explicado pelo fato de a eosina ser considerada um evidenciador que cora o biofilme bacteriano dental de forma mais fraca em relação a outros corantes, formando, portanto, uma margem de área menos definida do que a do CD (Silva et al. 2002). Com isso, pode ter ocorrido imprecisão, na avaliação computadorizada, na fase de seleção da área da superfície vestibular dental acometida por placa bacteriana e, também, na avaliação visual, o que explicaria a pouca diferença entre os dois métodos de avaliação. Nesse estudo foi utilizado o corante eosina aquosa a $2 \%$ seguindose a recomendação do padrão do modelo (Logan \& Boyce 1994); entretanto, estudos complementares com corantes que marcam a PB de forma mais intensa poderão demonstrar maior precisão nessa análise. Ainda há um amplo caminho a ser percorrido em relação à objetividade e precisão das avaliações de PB e CD da superfície vestibular.

Diante dos resultados deste estudo, pode-se sugerir que as seguintes questões sejam avaliadas em experimentos futuros: tipo de solução evidenciadora de PB, de forma a aumentar a distinção das áreas acometidas e a precisão da avaliação computadorizada; diminuição das faixas de escores dos índices da cavidade oral ou somente a utilização dos percentuais de área acometida por PB e CD; complementação da avaliação computadorizada com a inclusão de programa de computador para padronização da intensidade de coloração de PB (de acordo com o tipo de solução evidenciadora) e de CD.

Conclui-se que a avaliação computadorizada é vantajosa em relação à avaliação visual por conferir maior pre- cisão na obtenção da proporção entre área total do dente e área acometida e por mostrar-se estatisticamente superior na quantificação do cálculo dental após 28 dias.

Agradecimentos.- Os autores agradecem à Fundação de Amparo à Pesquisa do Estado do Rio de Janeiro pela disponibilização de verba para aquisição dos equipamentos e materiais de consumo para realização deste estudo. Ao Canil de experimentação do Laboratório de Quimioterapia Experimental em Parasitologia Veterinária do Departamento de Parasitologia Animal da Universidade Federal Rural do Rio de Janeiro. Ao senhor Henrique Lessa Abdalla pelo auxílio de conhecimento na área de informática.

\section{REFERÊNCIAS}

Beard G.B. \& Beard D.M. 1989. Geriatric dentistry. Vet. Clin. North Am., Small Anim. Pract. 19:49-74.

Bowersock T.L., Wu C.C., Inskeep G.A. \& Chester T. 2000. Prevention of bacteremia in dogs undergoing dental scaling by prior administration of oral clidamycin or chlorhexidine oral rinse. J. Vet. Dent. 17:11-16.

Corrêa H.L., Venturini M. \& Gioso M.A. 1998. Registro do exame clínico odontológico, odontograma. Clínica Veterinária 13:23-28.

DeBowes L.J., Mosier D., Logan E., Harvey C.E., Lowry S. \& Richardson D.C. 1996. Association of periodontal disease and histologic lesions in multiple organs from 45 dogs. J. Vet. Dent. 13:57-60.

DuPont G.A. 1997. Understanding dental plaque: Biofilm dynamics. J. Vet. Dent. 14:91-93.

Fantoni D.T. \& Cortopassi S.R.G. 2002. Anestesia em Cães e Gatos. Roca, São Paulo. 402p.

Gioso M.A. 2007. Odontologia Veterinária para o Clínico de Pequenos Animais. $2^{a}$ ed. Manole, São Paulo. 145p.

Gorrel C. \& Rawlings J.M. 1996. The role of tooth-brushing and diet in the maintenance of periodontal health in dogs. J. Vet. Dent. 13:139143.

Harvey C.E. \& Emily P.P. 1993. Small Animal Dentistry. Mosby, St Louis. $413 p$.

Harvey C.E. 2002. Shape and size of teeth of dogs and cats: Relevance to studies of plaque and calculus accumulation. J. Vet. Dent. 19:186195.

Hennet P. 1999. Review of studies assessing plaque accumulation and gingival inflammation in dogs. J. Vet. Dent. 16:23-29.

Hennet P., Servet E. \& Venet C. 2006. Effectiveness of an oral hygiene chew to reduce dental deposits in small breed dogs. J. Vet. Dent. 23:6-12.

Hull P.S. \& Davies R.M. 1972. The effect of chlorhexidine gel on tooth deposits in beagle dogs. J. Small Anim. Pract. 13:207-212.

Lindhe J., Hamp S.E. \& Löe H. 1975. Plaque induced periodontal disease in beagle dogs: A 4-year clinical, roentgenographical and histometrical study. J. Periodont. Res. 10:243-255.

Löe H. 1967. The gingival index, the plaque index and the retention index systems. J. Periodontol. 38:610-616.

Logan E.I. \& Boyce E.N. 1994. Oral health assessment in dogs: parameters and methods. J. Vet. Dent. 11:58-63.

Lund E.M., Armstrong J., Kirk C., Kolar L.M. \& Klausner J.S. 1999. Health status and population characteristics of dogs and cats examined at private veterinary practices in the United States. J. Am. Vet. Med. Assoc. 214:1336-1341.

Massone F. 1994. Técnicas anestésicas em cães, p.117-136. In: Massone F. (Ed.), Anestesiologia Veterinária: farmacologia e técnicas. $2^{\underline{a}}$ ed. Guanabara Koogan, Rio de Janeiro. 592p.

Michell P.Q. 2005. Odontologia de Pequenos Animais. São Paulo, Roca. $175 p$.

Rawlings J.M., Gorrel C. \& Markwell P.J. 1998. Effect on canine oral 
health of adding chlorhexidine to a dental hygiene chew. J. Vet. Dent. 15:129-134.

Scherl D.S., Coffman L., Van Cleave M. \& Lowry S. 2007. Validation of a new dental plaque quantification method in dogs. J. Vet. Dent. 24:1420.

Silva C.H.L., Paranhos H.F.O. \& Ito I.Y. 2002. Evidenciadores de biofilme em prótese total: avaliação clínica e antimicrobiana. Pesq. Odontol. Bras. 16:270-275.
Stoeken J.E., Versteeg P.A., Rosema N.A.M., Timmerman M.F., van der Velden U. \& van der Weijden G.A. 2007. Inhibition of "De Novo" plaque formation with $0.12 \%$ chlorexidine spray compared to $0.2 \%$ spray and $0.2 \%$ chlorexidine mouthwash. J. Periodontol. 78:899904.

VOHC (Veterinary Oral Health Council). 2008. The VOHC Seal of Acceptance. Disponível em URL: http://www.vohc.org. Acesso em 22.1.2008. 